\title{
Practice Burdens or Responsibilities?
}

Most of us hold opinions on contemporary issues in work practice, in all its broad dimensions. Sounding Board is a regular feature of this publication, designed to provide a forum for expressing such views, whether mainstream or controversial.

The opinions expressed in this section may not necessarily represent the views of the editor, the publisher, or the editorial board, but are intended to stimulate discussion or to provoke a response. Readers who wish to comment on the ideas put forth in Sounding Board should address their comments to the editor.

\author{
Frances Palmer, MS, OTR/L \\ Director, Rehabilitation Services \\ McLean Hospital \\ Belmont, Massachusetts
}

The revolution in health care revolves around neither technology nor new scientific discoveries. No, the revolution revolves around dollars, the payment of care. This is not a new phenomenon. Economics has always been a significant influence in our world.

How has the central factor of payment entered the clinical arena? For some of us in institutional practice, it has crept up on leaden feet. At many staffing conferences regarding a patient's treatment, the reality of payment takes priority, in decisions guiding delivery of care. What had once been a careful process of weighing life factors now is an expedient review that underscores medical liabilities. Given this reality, how does a clinician preserve therapeutic integrity?

The practice of rehabilitation has always required a central role for the patient. Since the rehabilitation effort is personal and dependent on the individual's goals, much of the clinician's involvement is as a consultant-a consultant who guides this individual through the sometimes tedious and often arduous climb toward recovery. Whether the disability is primarily physical or psychosocially based, the tasks of gaining command over one's life may be heroic but always private and personal.

In general, therapists achieve varying levels of proficiency within the role of consultant. During the early years of professional practice, a therapist is occupied with gaining basic skills. 
Technique and recognition from other professionals are sought and valued. The patient is framed within this perspective and seen as a channel for professional growth. It is only at a later point in one's practice that the patient moves from a source of professional experiences to a partner in the process of care and then to the leader who guides and implements the ingredients of care. At this later point, the therapist is secure in the limits of his or her professional impact and appreciative of the power of the human variable.

Psychiatric practice has been slow to accept the role as consultant to the patient. Years of parental approach toward patients and mystified explanations of mental illness contributed to maintaining the patient in the position of being "done to" rather than "worked with." Now, the single most influential factor in altering this professional perspective is the revolution of payment. The current payment crisis has brought the patient, family members, and therapists in partnership-a partnership that is vital in order to support the recovery efforts of individuals.

A new player in the arena of payment is the employer. More large companies are selfinsured and through their employee assistance program (EAP) staff have a connection to the patient. The employer has an investment in the recovery of the patient. This investment has a dual economic base. One consideration is the cost of an individual's lost work days. The other consideration is the cost of health care as a business expense. These economic realities are powerful forces in any decision that has an impact on the recovery from a major debilitating illness. Now added to the health care team is the employer. Does this diminish the position of the patient within the health care team? The potential is there for exactly that to occur.

The patient is surrounded by many players on this health care team. The professionals are well represented and the payors have gained representation as well. Each contributes pieces to the reality of the condition of the patient. Few argue when a diagnosis is made and fewer still dispute the ramifications that diagnosis may have on total functioning. Yet, when the intervention plans are determined, patients are faced with putting together pieces of their care and often forced to negotiate with many agencies. At times the health team relinquishes responsibility to the patient, family, or payor as if the health problem were no longer a responsibility but rather a burden.

Today, the burden to cope with the recovery process rests with patients. The patient may have an excellent support network or may be required to depend upon a system. In either circumstance, the individual will encounter a professional during the course of recovery. Whether that professional is responsive as a consultant to the patient will be contingent on the level of professional maturity. This is the critical point of interaction. If the professional does only a "technically accurate" job but falls short of listening to the goals of the patient, the efforts of recovery and rehabilitation will be lessened.

A technically accurate job is seen by many therapists as the limit of responsibility. The divisions of who is responsible for what are clearer in medicine than before, and each practitioner is concerned with overwhelming tasks faced during the course of a work day. The once esteemed therapeutic process or therapeutic use of self has taken a back seat to the competing demands of the job. And the job has become laced with such thoughts as how to protect oneself from burnout and limiting one's liability. Initial motivations for becoming a health care professional may need to be considered. Yet, conversely, there is no better time and place than the present in the arenas of rehabilitation. The partnership of care and concern are basic to the principles of rehabilitation.

These practice burdens may be perceived as opportunities to educate and to advocate. The opportunities to advocate for access and better levels of care are present with each professional interaction. In the context of our daily meetings, discussions with employers, family members, or other clinicians, we as therapists have the option to educate or to be silent. 